\title{
Detailed peptide profiling of "Scotta": from a dairy waste to a source of potential health-promoting compounds
}

\author{
Eduardo Sommella ${ }^{1,2}$ - Giacomo Pepe ${ }^{1,2}$. \\ Giovanni Ventre $^{2}$ - Francesco Pagano ${ }^{1,2}$. \\ Giulio Maria Conte ${ }^{2}$ - Carmine Ostacolo ${ }^{3}$. \\ Michele Manfra ${ }^{4}$ - Gian Carlo Tenore ${ }^{3}$. \\ Mariateresa Russo ${ }^{1}$ - Ettore Novellino ${ }^{3}$. \\ Pietro Campiglia $^{2,5}$
}

Received: 22 February 2016 /Revised: 3 June 2016 / Accepted: 6 June 2016 /

Published online: 21 June 2016

(C) INRA and Springer-Verlag France 2016

\begin{abstract}
Scotta" is a liquid waste deriving from Ricotta cheese production, which is wrongly considered only a dairy by-product. In this work, with the aim to elucidate the presence of valuable bioactive compounds in Buffalo's Scotta, a peptide fraction under $3000 \mathrm{Da}$ was isolated by ultra-filtration, purified by solid-phase extraction, and, subsequently, characterized in detail by liquid chromatography coupled to Orbitrap mass spectrometry. Analytical results revealed a complex profile, leading to the identification of 226 peptides, belonging to alpha, beta, and kappa caseins. A database-driven search approach was used to assess the biological effects of some of the identified peptides. A wide range of healthy properties was ascribed to the encrypted peptides, comprising antihypertensive, antimicrobial, immunomodulating, opioid, antioxidant, and antithrombotic. The peptidomic profile of Scotta was
\end{abstract}

Electronic supplementary material The online version of this article (doi:10.1007/s13594-016-0297-y) contains supplementary material, which is available to authorized users.

Pietro Campiglia

pcampiglia@unisa.it

1 Department of Agriculture, Laboratory of Food Chemistry, University of Reggio Calabria, Feo di Vito, 89100 Reggio, Calabria, Italy

2 Department of Pharmacy, School of Pharmacy, University of Salerno, Via Giovanni Paolo II 132, 84084 Fisciano, SA, Italy

3 Department of Pharmacy, University of Naples Federico II, Via D. Montesano 49, 80131 Naples, Italy

4 Department of Science, University of Basilicata, Viale dell'Ateneo Lucano 10, 85100 Potenza, Italy

5 European Biomedical Research Institute of Salerno, Via De Renzi 50, 84125 Salerno, Italy

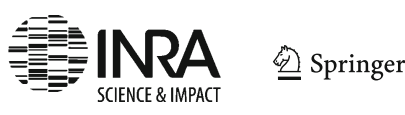


highlighted in depth for the first time, and the results revealed that this matrix should not be considered only a mere by-product, but a source of potential health-promoting peptides, which can be recovered and employed in nutraceuticals and functional foods.

Keywords Bioactive peptides · High-resolution mass spectrometry · Orbitrap · Peptidomics $\cdot$ Scotta

\section{Introduction}

Food waste and by-products represent one of the main challenges for agro-food industries, which must face demanding economic costs for their treatment and disposal. Moreover, they can be a risky source of pollution, especially when illegal methods are employed. In this regard, dairy industry produces, yearly, tons of by-products, whose main component is whey, which corresponds to the liquid fraction remaining after milk clotting. Whey constitutes a huge problem for disposal due to its elevated content of organic matter and associated high biochemical oxygen demand (BOD). On the other hand, whey has been recognized as a source of functional and bioactive compounds such as lactose, minerals, and, especially, proteins (Brandelli et al. 2015). In Italy, a small percentage of whey is employed for the production of Ricotta cheese, obtained by heating of the cheese whey at $85-90{ }^{\circ} \mathrm{C}$, thus leading to the precipitation and separation of whey proteins. The liquid fraction that remains after the cheese separation is called "Scotta," which is the main by-product of Ricotta production process. Scotta is generally composed by lactose (4.8-5.0\%), salts $(1.0-1.13 \%)$, and proteins $(0.15-0.22 \%)$ (Secchi et al. 2012). This by-product is considered, as well as whey, a significant source of pollution, possessing high values of BOD. While a weak interest in the recovery of Scotta has been focused on its conversion in bio-fuel and biotechnological substrate for fermented products (Sansonetti et al. 2009), almost nothing is known about the low-medium peptide fraction of this matrix so far. Since numerous bioactive peptides can be found in whey, a similar dairy waste, our study was focused on the identification of the peptides present in this by-product and the investigation, through database-driven approach, of their potential bioactivity. With the aim to elucidate the peptide profile of Scotta, in particular, the one deriving from buffalo ricotta-cheese processing, we carried out an in-depth characterization through a liquid chromatography-high-resolution mass spectrometry (LCHRMS) approach. A peptide fraction of 3000 Da was isolated and purified through ultrafiltration and solid-phase extraction (SPE); subsequently, the peptides were identified by LC-Orbitrap-based tandem mass spectrometry (MS/MS) with the help of online-driven database search for bioactivity assessment. A large number of potential bioactive peptides have been identified, still encrypted in the precursor oligopeptides, many with established health-promoting properties, including antihypertensive, antimicrobial, immunomodulatory, and antioxidant. These results could drive the dairy industry to its recovery, in order to reevaluate this waste product as a possible source for nutraceuticals and personalized functional foods. 


\section{Material and methods}

\subsection{Chemicals}

Ultra pure water $\left(\mathrm{H}_{2} \mathrm{O}\right)$ was obtained by a Milli-Q system (Millipore, Milan, Italy). The following chemicals were all purchased from Sigma-Aldrich (Milan, Italy): acetonitrile $(\mathrm{ACN})$ and formic acid $(\mathrm{HCOOH}) \mathrm{LC}-\mathrm{MS}$ grade. Centrifugal Filter Devices Amicon® Ultra-4 $3 \mathrm{~K}$ and $10 \mathrm{~K}$ and Strata- $\mathrm{X}^{\mathrm{TM}}$ polymeric reversed phase SPE $(500 \mathrm{mg} / 3 \mathrm{~mL})$ cartridge were purchased from Millipore ${ }^{\odot}$ and Phenomenex ${ }^{\circledR}$ (Castel Maggiore, Bologna, Italy), respectively, while filter paper Whatman® 540 from Sigma-Aldrich. Standard peptide mixture was purchased from Sigma-Aldrich.

\subsection{Sampling and sample preparation}

Buffalo's Scotta samples (500 mL each) were kindly donated by Di Lascio dairy factory (Capaccio, SA, Campania, Italy). The extraction was carried out in duplicate. Two samples were prepared by separating the residual fat fraction: $50 \mathrm{~mL}$ of Scotta was subjected to centrifugation at $4000 \times \mathrm{g}$ for $30 \mathrm{~min}$ at $4{ }^{\circ} \mathrm{C}$ (Mikro 220R, Hettich, Germany) and further filtered by a filter paper.

\subsection{Peptide fraction collection}

Ultrafiltration was carried out by Millipore's Amicon® Ultra-4 centrifugal filter devices at different cutoffs. A preliminary filtration was carried out for all the samples using filters with 10,000 nominal molecular weight limit (NMWL), and subsequently, $4 \mathrm{~mL}$ of permeate was loaded on devices with 3000 NMWL. The devices were centrifuged for $40 \mathrm{~min}$ at $6000 \mathrm{rpm}$ at $25^{\circ} \mathrm{C}$, using a centrifuge with fixed angle rotor $\left(35^{\circ}\right)$. In order to recover the peptides, the devices were washed with $4 \mathrm{~mL}$ of acidified water at $\mathrm{pH} 3.0$ by formic acid. A peptide fraction, roughly $3.5 \mathrm{~mL}$, with molecular weight $\leq 3000$ Da was collected, filtered through a $0.45-\mu \mathrm{m}$ pore cellulose membrane (Millipore $^{\odot}$ ), and lyophilized for $24 \mathrm{~h}$ (LyoQuest-55, Telstar Technologies, Spain).

\subsection{Solid-phase extraction}

To remove salts and sugars, we employed a polymeric reversed phase cartridge, since this sorbent was more efficient in the purification of the peptide fraction instead of $\mathrm{C} 18$ cartridge (data not shown). The peptide fraction was solubilized in $0.1 \%(v / v)$ aqueous trifluoroacetic acid (TFA) and loaded on a Strata-X $\mathrm{X}^{\mathrm{TM}}$ reversed phase polymeric SPE cartridge (Phenomenex $\AA$ ), previously equilibrated in $0.1 \%$ TFA, then eluted with 70 / $30 / 0.1 \mathrm{ACN} /$ water/TFA $(v / v / v)$, and finally re-lyophilized and stored at $-20{ }^{\circ} \mathrm{C}$. Lyophilized samples were solubilized in water and injected.

\subsection{LC-HRMS analysis of peptide fraction}

Peptide separation and identification were performed on an Accela 600 LC system coupled on-line to an LTQ Orbitrap XL mass spectrometer (Thermo Scientific, Bremen, Germany) through an electrospray source. For peptide separation, an Ascentis® 
Express Peptide ES C18 $150 \mathrm{~mm} \times 2.1 \mathrm{~mm}(L \times$ ID), $2.7 \mu \mathrm{m} 160 \AA$ (Supelco, Bellefonte, PA, USA), was employed. Mobile phases were $0.1 \% \mathrm{HCOOH}$ in $\mathrm{H}_{2} \mathrm{O}$ $v / v$ (A) and ACN plus $0.1 \% \mathrm{HCOOH} v / v(\mathrm{~B})$. LC gradient was the following: 0$22 \mathrm{~min}, 0-30 \% \mathrm{~B}, 22-27 \mathrm{~min}, 30-70 \% \mathrm{~B}, 27-28 \mathrm{~min}, 70-95 \% \mathrm{~B}$, isocratic for $1 \mathrm{~min}$, 29-34 min, returning to $0 \% \mathrm{~B}$. Flow rate was set to $0.3 \mathrm{~mL} \cdot \mathrm{min}^{-1}$. Column oven was set to $45{ }^{\circ} \mathrm{C}$. Two microliters of sample was injected. For the MS part, spray voltage was set at $+3.5 \mathrm{kV}$, sheath gas arbitrary units 30 , auxiliary gas arbitrary units 10 , and capillary temperature $250{ }^{\circ} \mathrm{C}$. MS/MS spectra were collected in data-dependent mode, over the $m / z$ range of 300-2000, at 30,000 resolution. All MS/MS spectra were collected using a normalized collision energy of $35 \%$ and an isolation window of 2 $\mathrm{m} / \mathrm{z}$, minimum signal threshold 150 , and monoisotopic precursor enabled. Ion trap and Orbitrap maximum ion injection times were set to 50 and $100 \mathrm{~ms}$, respectively. Automatic gain control was used to prevent over-filling of the ion traps and was set to $2 \times 10^{5}$ for full FTMS scan and $3 \times 10^{4}$ ions in MS/MS mode for the linear ion trap. Dynamic exclusion was enabled with a repeat count of 1 and a repeat duration of $30 \mathrm{~s}$, list size 50, with exclusion duration of $30 \mathrm{~s}$. All parameters were optimized by infusion of a standard peptide mixture at $20 \mu \mathrm{L} \cdot \mathrm{min}^{-1}$.

\subsection{Peptide sequence identification}

Raw MS/MS data files from Xcalibur software (Thermo Fisher Scientific) were converted in mzXML format, and a free trial of PEAKS 7.5 software (Bioinformatics Solutions Inc., Waterloo, Canada) was employed for sequence determination. Search was performed using a database search tool, by searching against Swiss-Prot/UniProt database (Release 2015_11) taxonomy mammals, with an improved algorithm that validates and assists the database search with de novo sequencing results. For database search, the following settings were chosen: digestion with no enzyme and peptide charges from +1 to +4 , precursor mass search type: monoisotopic, fragmentation mode: $\mathrm{CID}$ (y and $\mathrm{b}$ ions), and precursor mass tolerance $15 \mathrm{ppm}$ and fragment mass tolerance of $0.5 \mathrm{Da}$; oxidation $(\mathrm{M})$ and phosphorylation $(\mathrm{S}, \mathrm{T}, \mathrm{Y})$ were used as dynamic modifications; no static modification was selected. The LC-MS/MS injections were performed in triplicate. Identifications were accepted if the peptides were detected in at least two of the three replicates. To assess the bioactivity, all identified peptides were searched against the following free online databases: BIOPEP (http://www.uwm.edu. pl/biochemia/index.php/pl/biopep), milkAMP (http://milkampdb.org/home.php), and EROP-Moscow (http://erop.inbi.ras.ru/).

\section{Results and discussion}

\subsection{Sample isolation and peptide sequence determination}

The growing interest in health-promoting molecules from food matrices pushes the research in the recovery of these bioactive compounds also from food processing materials and by-products. MS-based peptidomic approaches are the best strategies to characterize and monitor dairy bioactive peptides (Sánchez-Rivera et al. 2014). The interest in Scotta has been mainly restricted to the possible conversion of the matrix into 
bioethanol or for lactose production (Pisponen et al. 2013). Contrariwise, in this study, we focused on the isolation of peptides under $3000 \mathrm{Da}$, since many bioactive casein peptides are comprised in this range (Sánchez-Rivera et al. 2014). Peptide identification was performed through LC-MS/MS. The total ion chromatogram (TIC) relative to the separation of the isolated peptide fraction is depicted in Fig. 1. The complete list of peptides including retention time, peptide sequence, precursor protein, position, and mass is reported in supplementary Table S1. As it can be appreciated from the TIC, a very complex profile was obtained. Despite this, the employment of a fused-core particle column provided a satisfactory and fast separation with an analysis time of 34 min, which led to the identification of 226 peptides, belonging to buffalo caseins (CN) $\alpha_{\mathrm{s} 1}, \beta$, and $\mathrm{k}$ (UniProt Entries: O62823, Q9TSI0, P11840). No peptides belonging to $\alpha_{\mathrm{s} 2}-\mathrm{CN}$ were detected, neither peptides deriving from whey proteins, since the thermal coagulation process leads to their incorporation into cheese. It is noteworthy that the only previous investigation on Scotta led to the identification of only 29 peptides (De Simone et al. 2009). This significant difference cannot be solely explained by a different processing method used by the factory but should be ascribed to a different analytical setup. All the previously identified peptides have been detected in this investigation. The suitability of the Orbitrap-MS analyzers for peptidomics has been, in fact, widely demonstrated (Capriotti et al. 2016).

\subsection{The peptidomic profile of Scotta}

Most peptides originated from $\beta-\mathrm{CN}(47 \%)$ followed by $\alpha_{\mathrm{s} 1}(40.5 \%)$ and $\mathrm{k}(12.5 \%)$. These data confirm a major degradation of $\beta-\mathrm{CN}$, in particular at the $\mathrm{C}$-terminal portion with $\mathrm{L}^{192} \mathrm{Y}^{193}$ and $\mathrm{Y}^{193}-\mathrm{Q}^{194}$ residues together with the $\mathrm{N}$-terminal portion with $\mathrm{A}^{1}-\mathrm{R}^{2}$

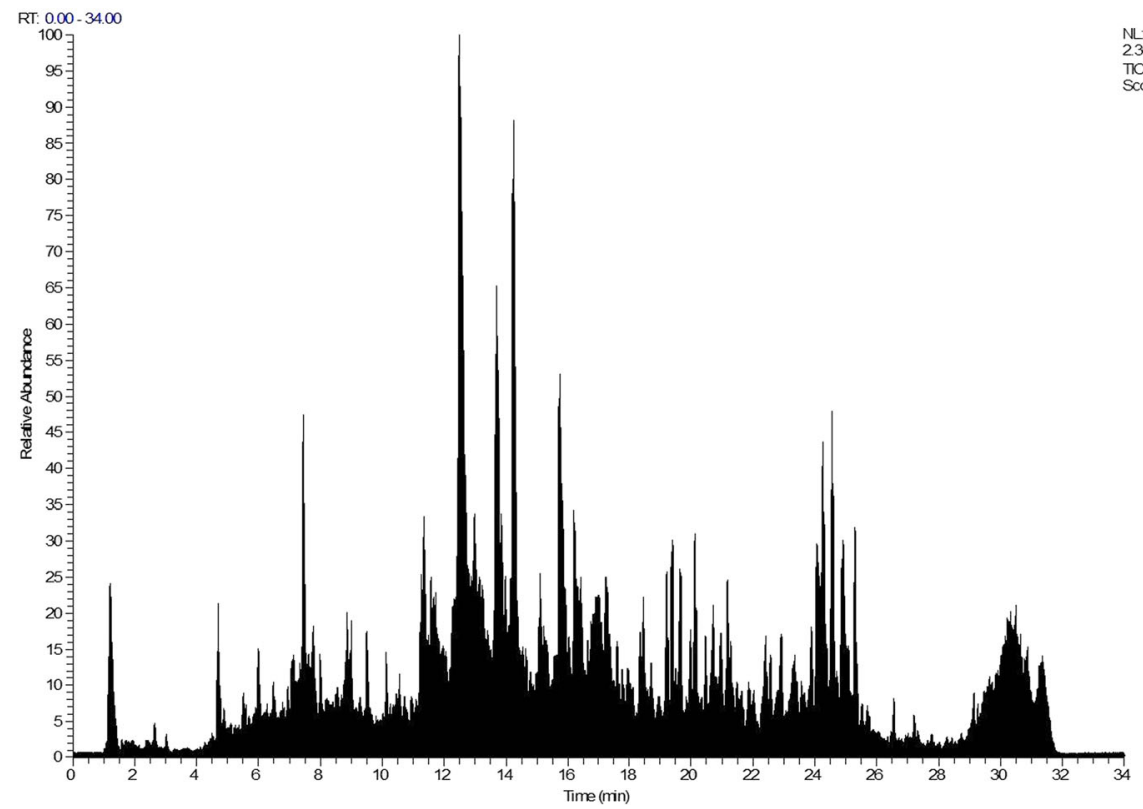

Fig. 1 Total ion chromatogram relative to the analysis of peptide fraction $\leq 3000 \mathrm{Da}$ of Scotta. Column: Ascentis ${ }^{\circledR}$ Express Peptide ES C18 150 mm × 2.1 mm, $2.7 \mu \mathrm{m} 160 \AA$ A. Detection: Orbitrap-MS 
residues, which are more susceptible to cleavage, probably by amino- and carboxypeptidases, as observed previously (Baum et al. 2013). Also, $\alpha_{\mathrm{s} 1}-\mathrm{CN}$ was prone to degradation at the $\mathrm{N}$-terminal portion, within the region comprising residues $\mathrm{A}^{1}-\mathrm{R}^{2}$ and, in particular, $\mathrm{F}^{23}-\mathrm{F}^{24}$ and $\mathrm{F}^{24}-\mathrm{V}^{25}$, which are known to be subject of cleavage by chymosin and cathepsin B, respectively. Kappa-CN was mainly represented by peptides deriving from k-CN macropeptide $\mathrm{f}(106-169)$, especially in the region containing residues $\mathrm{N}^{113}-\mathrm{Q}^{114}$. The sequence coverage was $83 \%$ for $\beta-\mathrm{CN}, 49 \%$ for $\alpha_{\mathrm{s} 1}-\mathrm{CN}$, and $41 \%$ for k-CN (supplementary Fig. S1). All the identified peptides were comprised in the range of 500-3000 Da (Fig. 2c).

\subsection{Potential bioactive peptides in Scotta}

As shown in Fig. 2a, b, a wide range of health-promoting properties can be attributed to Scotta peptides, many of them showing multifunctional activity. Table 1 shows the identified bioactive peptides reported in literature. It must be pointed out that many bioactive sequences are still encrypted in precursor oligopeptides, but they can be further released by the action of peptidases, as often occurs in gastrointestinal digestion process.

\subsection{ACE inhibitory peptides}

Numerous recognized anti-ACE peptides have been identified. Among them, the $\alpha_{\mathrm{s}_{1}}{ }^{-}$ CN peptide with sequence FVAPFPEVFG f(24-33) has been reported to exhibit strong ACE inhibitory activity (Robert et al. 2004), together with a large number of $\beta$-CN-

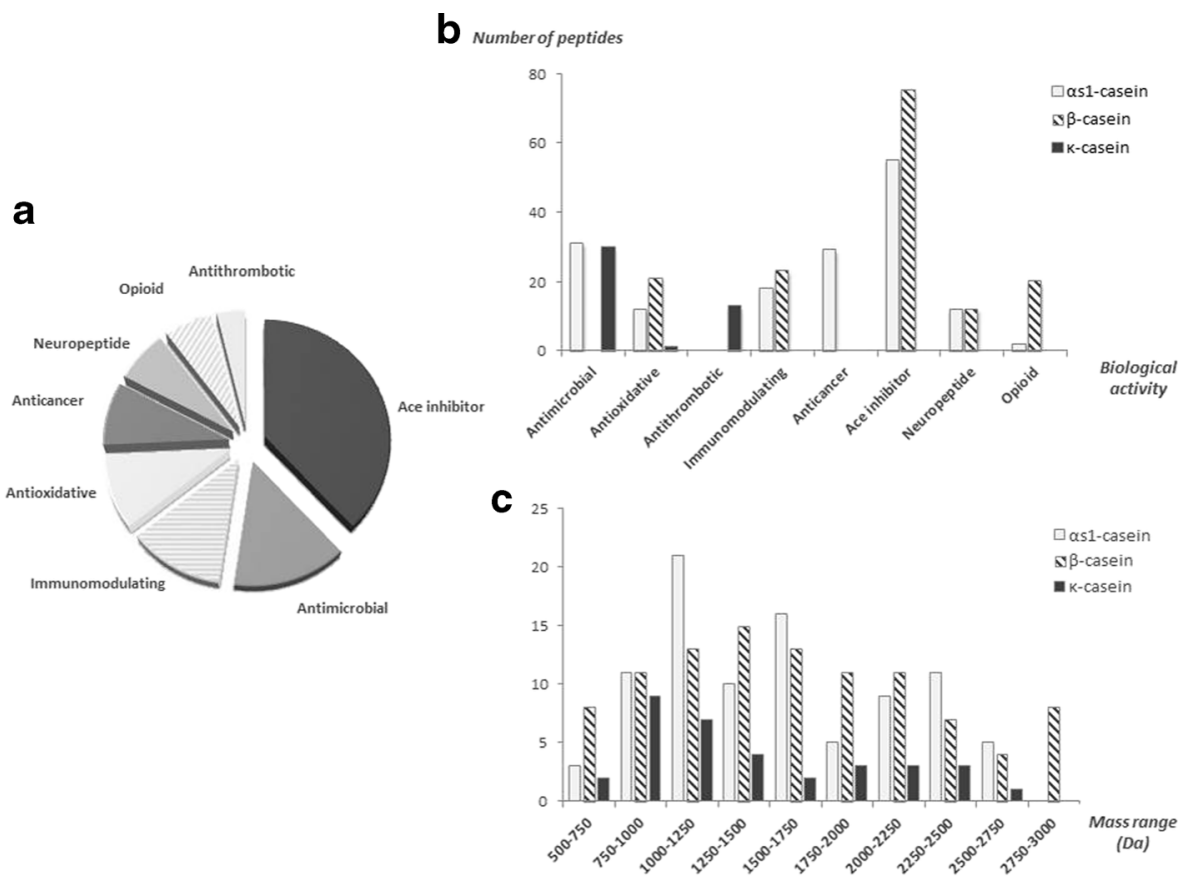

Fig. 2 Bioactive properties of identified peptides (a), relative contribution of each protein and corresponding peptides (b), and mass range order of the identified peptides (c) 
Table 1 Bioactive peptides identified in Scotta

\begin{tabular}{|c|c|c|c|c|}
\hline Activity & Position & Casein & Peptide Sequence & References \\
\hline \multicolumn{5}{|c|}{ ACE inhibitor } \\
\hline & $24-33$ & $\alpha_{\mathrm{s} 1}$ & FVAPFPEVFG & Robert et al. (2004) \\
\hline & $23-34$ & $\alpha_{\mathrm{s} 1}$ & FFVAPFPEVFGK & Robert et al. (2004) \\
\hline \multicolumn{5}{|c|}{ Antimicrobial } \\
\hline & $15-22$ & $\alpha_{\mathrm{s} 1}$ & VLNENLLR & Hayes et al. (2006) \\
\hline \multicolumn{5}{|c|}{ ACE inhibitor, immunomodulating } \\
\hline & 193-209 & $\beta$ & YQEPVLGPVRGPFPIIV & Yamamoto et al. (1994); Coste et al. (1992) \\
\hline \multicolumn{5}{|c|}{ Antioxidant } \\
\hline & $80-90$ & $\alpha_{\mathrm{s} 1}$ & HIQKEDVPSER & Gupta et al. (2010) \\
\hline
\end{tabular}

For encrypted bioactive sequences, please see Table S1

derived peptides, for instance, NLHLPLPLLQ f(132-141), which contains the sequence LHLPLP that showed antihypertensive effect in rats (Miguel et al. 2006), and SLPQNIPPLTQTPV f(69-82) (Yamamoto et al. 1994). Neither of them was detected in the previous investigation on Scotta.

\subsection{Antimicrobial peptides}

Also, antimicrobial peptides (AMPs) were found in the sample. In this regard, particularly useful was the search against the milkAMP database (Théolier et al. 2014). Several fragments belong to $\alpha_{\mathrm{s} 1-} \mathrm{CN} \mathrm{f}(1-23)$, which shares some residues with the cow variant $\mathrm{f}(1-23)$ (isracidin) reported as antimicrobial (Lahov and Regelson 1996) and known to be subjected to chymosin cleavage. The shorter peptides, such as the caseicin B with sequence VLNENLLR f(15-22), showing activity against Escherichia coli at very low concentration (Hayes et al. 2006), could derive both from lactic acid bacteria peptidases and from rennet enzyme action. The $\alpha_{\mathrm{s} 1}$ buffalo variant fragment 1-23 presents two amino acid substitutions $\left(\mathrm{H}^{4}-\mathrm{Q}\right.$ and $\left.\mathrm{E}^{14}-\mathrm{G}\right)$; therefore, the activity of these sequences should be confirmed. Among potential AMPs, numerous k-CN-derived fragments were found. In particular, the peptide AVRSPAQIL $\mathrm{f}(65-73)$ and the Nterminal portion $\mathrm{f}(105-122)$, deriving from peptide Kappacin $\mathrm{f}(106-169)$, were detected (López-Expósito et al. 2006), together with another peptide, namely QVTSTVV $\mathrm{f}(162-168)$, which is very similar to the C-terminal portion of Kappacin, which has been reported to possess antimicrobial activity. The antimicrobial activity of peptide QVTSTVV should be further investigated, since the buffalo variant possesses an amino acid variation $\left(\mathrm{V}^{167}-\mathrm{A}\right)$. Moreover, an antithrombotic function was reported for the $\mathrm{k}$ CN peptide MAIPPKKNQ f(105-113) (Jolles et al. 1986). Kappa-CN fragments f(6573 ) and $\mathrm{f}(105-113)$ had not been detected before in Scotta.

\subsection{Multifunctional peptides}

Several peptides identified in the present investigation are characterized by a multifunctional activity. A clear example is casecidin $17, \beta-\mathrm{CN} \mathrm{f}(193-209)$, which 
exerts both anti-ACE (Yamamoto et al. 1994) and immunomodulating activities (Coste et al. 1992). In addition, also, the $\beta$-CN peptide LVYPFPGPIPK $\mathrm{f}(58-68)$ showed both anti-ACE and opioid activities, similarly to the $\alpha_{\mathrm{s} 1}-\mathrm{CN} \mathrm{f}(86-99)$ VPSERYLGYLEQLL, which includes $\alpha_{\mathrm{s} 1}-\mathrm{CN}$ f(90-95) peptide with sequence RYLGYL, known as $\alpha$-Casomorphin 6 (Loukas et al. 1983). The latter has not been previously reported in Scotta. Also present were antioxidant peptides, such as $\beta-\mathrm{CN}$ sequence $\mathrm{f}(98-106)$ and $\alpha_{\mathrm{s} 1}-\mathrm{CN}$ f(80-90) (Gupta et al. 2010). Many other sequences have been identified in the sample, which are reported to provide other possible health benefits. To perform their activity, peptides must be absorbed in the intestinal tract and reach the systemic circulation. Nevertheless, if not absorbed, they can exert their functions on the local tissue or by binding to intestinal receptors. In this regard, several of the identified peptides have been detected in vivo, in the gastrointestinal tract, of both animal models and humans, after digestion of dairy matrices (Barbé et al. 2014; Boutrou et al. 2013). The activity of the identified peptides has been described by in vitro models in many of the reported papers; for this reason, in vivo and bioavailability studies are mandatory to understand in depth their mechanisms. Furthermore, many of the identified caseins peptides possess a high homology with the cow variant; thus, their activity may be very similar but should be further investigated. The isolation and purification of the different peptide fractions will be the following steps to elucidate and confirm the predicted biologic activity, together with the quantification of the most relevant peptides by multiple reaction monitoring (MRM) techniques. Although the protein content in Scotta is low, on average, $0.2 \%$, high amounts of peptides can be easily recovered, since the production of this by-product can reach 1.0 Mt per year, and could be employed in nutraceuticals or personalized and enriched functional foods.

\section{Conclusion}

Similarly to whey, Scotta cannot be considered only a mere waste product of dairy industry. Our approach, based on the isolation of a peptide fraction $\leq 3000 \mathrm{Da}$, and subsequent LC-HRMS-based method have revealed a high complex profile. The peptidomic analysis highlighted a wide presence of valuable potential bioactive peptides, with recognized possible health benefits. These results could drive the dairy industry toward the recovery of Scotta, in order to turn this waste product into a possible source of bioactive peptides that could be potentially included in nutraceutical formulations and functional foods.

Acknowledgments The authors would like to thank for the financial support the project 300390 PON13TERINA: "Research Infrastructure for Foods and Nutriceutics."

\section{Compliance with ethical standards}

Conflict of interest The authors declare that they have no conflict of interests.

Ethical approval This article does not contain any studies with human participants or animals performed by any of the authors. 


\section{References}

Barbé F, Le Feunteun S, Rémond D, Ménard O, Jardin J, Henry G, Laroche B, Dupont D (2014) Tracking the in vivo release of bioactive peptides in the gut during digestion: mass spectrometry peptidomic characterization of effluents collected in the gut of dairy matrix fed mini-pigs. Food Res Int 63:147-156

Baum F, Fedorova M, Ebner J, Hoffmann R, Pischetsrieder M (2013) Analysis of the endogenous peptide profile of milk: identification of 248 mainly casein-derived peptides. J Proteome Res 12:5447-5462

Boutrou R, Gaudichon C, Dupont D, Jardin J, Airinei G, Marsset-Baglieri A, Benamouzig R, Tome' D, Leonil $\mathrm{J}$ (2013) Sequential release of milk protein-derived bioactive peptides in the jejunum in healthy humans. Am J Clin Nutr 97:1314-1323

Brandelli A, Daroit DJ, Folmer Corrêa AP (2015) Whey as a source of peptides with remarkable biological activities. Food Res Int 73:149-161

Capriotti AL, Cavaliere C, Piovesana S, Samperi R, Laganà A. (2016) Recent trends in the analysis of bioactive peptides in milk and dairy products. Anal Bioanal Chem 1-9 doi: 10.1007/s00216-016-9303-8

Coste M, Rochet V, Léonil J, Mollé D, Bouhallab S, Tomé D (1992) Identification of C-terminal peptides of bovine $\beta$-casein that enhance proliferation of rat lymphocytes. Immunol Lett 33:41-46

De Simone C, Picariello G, Mamone G, Stiuso P, Dicitore A, Vanacore D, Chianese L, Addeo F, Ferranti P (2009) Characterisation and cytomodulatory properties of peptides from Mozzarella di Bufala Campana cheese whey. J Pept Sci 15:251-258

Gupta A, Mann B, Kumar R, Sangwan RB (2010) Identification of antioxidant peptides in Cheddar cheese made with adjunct culture Lactobacillus casei ssp. Casei 300. Milchwissenschaft 65:396-399

Hayes M, Ross RP, Fitzgerald GF, Hill C, Stanton C (2006) Casein-derived antimicrobial peptides generated by Lactobacillus acidophilus DPC6026. Appl Environ Microbiol 72:2260-2264

Jolles P, Levy-Toledano S, Fiat AM, Soria C, Gillessen D, Thomaidis A, Dunn FW, Caen JP (1986) Analogy between fibrinogen and casein effect of an undecapeptide isolated from rc-casein on platelet function. Eur J Biochem 158:379-382

Lahov E, Regelson W (1996) Antibacterial and immunostimulating casein-derived substances from milk: casecidin, isracidin peptides. Food Chem Toxicol 34:131-145

López-Expósito I, Minervini F, Amigo L, Recio I (2006) Identification of antibacterial peptides from bovine kappa-casein. J Food Prot 69:2992-2997

Loukas S, Varoucha D, Zioudrou C, Streaty RA, Klee WA (1983) Opioid activities and structures of alphacasein-derived exorphins. Biochemistry 22:4567-4573

Miguel M, Recio I, Ramos M, Delgado MA, Aleixandre MA (2006) Antihypertensive effect of peptides obtained from Enterococcus faecalis-fermented milk in rats. J Dairy Sci 89:3352-3359

Pisponen A, Pajumägi S, Mootse H, Karus A, Poikalainen V (2013) The lactose from Ricotta cheese whey: the effect of $\mathrm{pH}$ and concentration on size and morphology of lactose crystals. Dairy Sci Technol 93:477486

Robert MC, Razaname A, Mutter M, Juillerat MA (2004) Identification of angiotensin-I-converting enzyme inhibitory peptides derived from sodium caseinate hydrolysates produced by Lactobacillus helveticus NCC 2765. J Agric Food Chem 52:6923-6932

Sánchez-Rivera L, Martínez-Maqueda D, Cruz-Huerta E, Miralles B, Recio I (2014) Peptidomics for discovery, bioavailability and monitoring of dairy bioactive peptides. Food Res Int 63:170-181

Sansonetti S, Curcio S, Calabrò V, Iorio G (2009) Bio-ethanol production by fermentation of ricotta cheese whey as an effective alternative non-vegetable source. Biomass Bioenergy 33:1687-1692

Secchi N, Giunta D, Pretti L, Ruiz García M, Roggio T, Mannazzu I, Catzeddu P (2012) Bioconversion of ovine scotta into lactic acid with pure and mixed cultures of lactic acid bacteria. J Ind Microbiol Biotechnol 39:175-181

Théolier J, Fliss I, Jean J, Hammami R (2014) MilkAMP: a comprehensive database of antimicrobial peptides of dairy origin. Dairy Sci Technol 94:181-193

Yamamoto N, Akino A, Takano T (1994) Antihypertensive effect of the peptides derived from casein by an extracellular proteinase from Lactobacillus helveticus CP790. J Dairy Sci 77:917-922 